\title{
Predicting long-term sickness absence and early retirement pension from self-reported work ability
}

Lea Sell · Ute Bültmann · Reiner Rugulies •

Ebbe Villadsen · Anne Faber $\cdot$ Karen Søgaard

Published online: 5 May 2009

(C) Springer-Verlag 2009

\section{Erratum to: Int Arch Occup Environ Health \\ DOI 10.1007/s00420-009-0417-6}

Unfortunately, the co-authors names were missed in the author group of the online published article. The corrected version of author group and their affiliations are given below.

\section{Author Group}

Lea Sell, Ute Bültmann, Reiner Rugulies, Ebbe Villadsen, Anne Faber, Karen Søgaard

\section{Affiliations}

Lea Sell, Reiner Rugulies, Ebbe Villadsen, Anne Faber National Research Centre for the Working Environment, Lersø Parkallé 105, 2100 Copenhagen, Denmark

The online version of the original article can be found under doi: 10.1007/s00420-009-0417-6.

L. Sell $(\varangle) \cdot$ R. Rugulies $\cdot$ E. Villadsen · A. Faber

National Research Centre for the Working Environment, Lersø Parkallé 105, 2100 Copenhagen, Denmark

e-mail: 1se@nrcwe.dk

\section{U. Bültmann}

Department of Health Sciences,

University Medical Center Groningen, Antonius Deusinglaan 1,

Building 3217, Room 605, 9713 AV Groningen, The Netherlands

\section{K. Søgaard}

Institute of Sports Science and Clinical Biomechanics,

University of Southern Denmark, Campusvej 55,

5230 Odense M, Denmark
Ute Bültmann

Department of Health Sciences, University Medical Center Groningen, Antonius Deusinglaan 1, Building 3217, Room 605, 9713 AV Groningen, The Netherlands

Karen Søgaard

Institute of Sports Science and Clinical Biomechanics, University of Southern Denmark, Campusvej 55, 5230 Odense M, Denmark 